\title{
Free-Form-Fabricated Commercially Pure Ti and Ti6Al4V Porous Scaffolds Support the Growth of Human Embryonic Stem Cell-Derived Mesodermal Progenitors
}

\author{
G. M. de Peppo, ${ }^{1,2}$ A. Palmquist, ${ }^{1,2}$ P. Borchardt, ${ }^{2,3}$ M. Lennerås, ${ }^{2}$ J. Hyllner,, 4 \\ A. Snis, ${ }^{5}$ J. Lausmaa, ${ }^{2,3}$ P. Thomsen, ${ }^{1,2}$ and C. Karlsson ${ }^{1,2}$ \\ ${ }^{1}$ Department of Biomaterials, Sahlgrenska Academy at University of Gothenburg, P.O. Box 412, 41346 Göteborg, Sweden \\ ${ }^{2}$ BIOMATCELL VINN Excellence Center of Biomaterials and Cell Therapy, 41346 Göteborg, Sweden \\ ${ }^{3}$ SP Technical Research Institute of Sweden, 50115 Borås, Sweden \\ ${ }^{4}$ Research and Development Division, Cellartis $A B, 41346$ Göteborg, Sweden \\ ${ }^{5}$ Research and Development Division, Arcam AB, 43137 Göteborg, Sweden \\ Correspondence should be addressed to G. M. de Peppo, giuseppe.de.peppo@biomaterials.gu.se
}

Received 24 September 2011; Accepted 15 October 2011

Academic Editor: Farzad Esni

Copyright ( 2012 G. M. de Peppo et al. This is an open access article distributed under the Creative Commons Attribution License, which permits unrestricted use, distribution, and reproduction in any medium, provided the original work is properly cited.

\begin{abstract}
Commercially-pure titanium (cp-Ti) and the titanium-aluminum-vanadium alloy (Ti6Al4V) are widely used as reconstructive implants for skeletal engineering applications, due to their good mechanical properties, biocompatibility and ability to integrate with the surrounding bone. Electron beam melting technology (EBM) allows the fabrication of customized implants with tailored mechanical properties and high potential in the clinical practice. In order to augment the interaction with the biological tissue, stem cells have recently been combined with metallic scaffolds for skeletal engineering applications. We previously demonstrated that human embryonic stem cell-derived mesodermal progenitors (hES-MPs) hold a great potential to provide a homogeneous and unlimited supply of cells for bone engineering applications. This study demonstrates the effect of EBM-fabricated cp$\mathrm{Ti}$ and Ti6Al4V porous scaffolds on hES-MPs behavior, in terms of cell attachment, growth and osteogenic differentiation. Displaying different chemical composition but similar surface properties, EBM-fabricated cp-Ti and Ti6Al4V scaffolds supported cell attachment and growth, and did not seem to alter the expression of genes involved in osteogenic differentiation and affect the alkaline phosphatase activity. In conclusion, interfacing hES-MPs to EBM-fabricated scaffolds may represent an interesting strategy for design of third-generation biomaterials, with the potential to promote implant integration in clinical conditions characterized by poor bone quality.
\end{abstract}

\section{Introduction}

Bone engineering aims at fabricating bone substitutes for the reconstruction of skeletal defects caused by degenerative disorders and trauma [1]. Hard materials, such as metals and their alloys, have been extensively used as load-bearing and reconstructive implants for skeletal engineering applications [2]. cp-Ti and the Ti6Al4V alloy are mainly employed due to their biocompatibility and good mechanical properties [3], as well as the ability to become osseointegrated by forming a direct contact with the surrounding bone [4-6]. Moreover, both the $\mathrm{cp}$-Ti and Ti6Al4V alloy form a passive oxide layer at the surface, which imparts resistance to corrosion after implantation in the human body [7]. However, when in contact with physiological solutions both cp-Ti and Ti6Al4V tend to release metal ions, raising concerns about the possible cytotoxic effects associated with leaching of vanadium from the Ti6Al4V alloy $[8,9]$.

In many cases, a complex three-dimensional (3D) geometry of the implantable device is needed for an optimal clinical outcome [10]. Furthermore, a certain degree of porosity may facilitate bone ingrowth and remodeling throughout the implant, eventually enhancing bone-material contact and 
stability. Implant porosity also allows reducing stiffness mismatch between bone and the implanted material, hence helps to avoid stress-shielding effects [11]. Complex porous 3D metallic parts are currently manufactured using innovative free-form fabrication (FFF) techniques, such as 3D printing [12], sacrificial wax template [13], 3D fiber deposition technique [14], selective laser melting [15], selective laser sintering [16], direct metal deposition [17], and electron beam melting (EBM) [18-20]. Among these, EBM represents a promising technique for the high-speed and high-volume fabrication of customized metallic implants with excellent properties for personalized applications in skeletal engineering [20].

The possibility to interface stem cells to implants before implantation has been explored in order to augment bone ingrowth and promote osseointegration [21]. Human mesenchymal stem cells (hMSCs), which reside in the bone marrow [22] and other adult tissues [23-26], have been largely used for tissue engineering applications and recently combined with metallic scaffolds for bone engineering applications [27-30]. However, hMSCs manifest important limitations for the large-scale production of cells for clinical applications, especially considering harvesting, isolation, and enrichment procedures, which result in a high degree of heterogeneity $[31,32]$, as well as the limited proliferation potential and the loss of functionality observed after protracted expansion [33-35]. An alternative to hMSCs is the use of human stem cell-derived mesodermal progenitors (hES-MPs), which do not form teratoma and resemble hMSCs in terms of gene expression and lineage commitment but display higher regeneration potential [35-37], which is fundamental for the bulk production of functional cells for engineering applications. However, for a potential clinical use of hES-MPs in skeletal engineering applications, the understanding of their behavior when interfaced with $3 \mathrm{D}$ metallic scaffolds in vitro is crucial, but no information about this is available today.

In the present study, we interfaced hES-MPs with EBMfabricated 3D cp-Ti and Ti6Al4V porous scaffolds, with the aim of investigating the effect of these materials in influencing the hES-MPs ability to attach, grow, and differentiate toward the osteogenic lineage.

\section{Material and Methods}

2.1. Free-Form Fabrication. The free-form-fabricated scaffolds were produced in an Arcam EBM S12 system (Arcam AB, Mölndal, Sweden; http://www.arcam.com/) from standard Arcam cp-Ti and Ti6Al4V extra low interstitial powders with a particle size of $45-100 \mu \mathrm{m}$. The cubic scaffolds were made from the 3D computer-aided design (CAD) model shown in Figure 1(a), with each side measuring approximately $6.8 \mathrm{~mm}$. In Figure $1(\mathrm{~b})$, a photograph of the EBMfabricated scaffolds is shown. The electron beam melts the powder in a layer-by-layer process with a layer thickness of $0.1 \mathrm{~mm}$. All the scaffolds were produced in two separate builds, one for Ti6Al4V and one for cp-Ti. The building temperature of the powder bed was $750^{\circ} \mathrm{C}$ for Ti6Al4V and $700^{\circ} \mathrm{C}$ for $\mathrm{cp}-\mathrm{Ti}$, respectively. The vacuum pressure inside the chamber was $2 \times 10^{-3}$ mbar for both builds. The control settings of the build process were in accordance with standard settings provided by Arcam AB. After building, the scaffolds were cooled in an He environment at a pressure of $2 \times 10^{2}$ mbar until they reached a temperature of about $100^{\circ} \mathrm{C}$. Air was then introduced into the chamber. All scaffolds were finally blasted with the same cp-Ti and Ti6Al4V ELI powders they were built of. Both the cp-Ti and Ti6Al4V had an average pore size of $620 \mu \mathrm{m}$ in diameter and a volume porosity of about $70-75 \%$. All pores were interconnected [38].

2.2. Cleaning and Sterilization. After blasting, the scaffolds were ultrasonically treated in order to remove impurities. First they were ultrasonically cleaned for 5 minutes each in two successive baths of MIS 024 (Tremedic AB, Göteborg, Sweden), then three times for $5 \mathrm{~min}$ in ELGA/Milli-Q water (Tremedic AB). After this, the scaffolds were let to dry in air in a sterile environment. The scaffolds were then sealed in sterile bags and steam autoclaved for $15 \mathrm{~min}$ at $120^{\circ} \mathrm{C}$.

2.3. Surface Analysis of Scaffolds. Surface topography of native scaffolds was investigated by scanning electron microscopy (SEM), using a Leo Ultra 55 FEG SEM (Leo Electron Microscopy Ltd., Cambridge, UK) equipped with a secondary electron detector and an in-lens detector. Overview images were acquired in the secondary electron imaging mode at $5 \mathrm{kV}$ acceleration voltage. The in-lens detector was used for closer examination of the samples at $2 \mathrm{kV}$ acceleration voltage.

Surface composition and oxide thickness was analyzed by time-of-flight secondary ion mass spectroscopy (TOFSIMS) using a TOF-SIMS IV instrument (ION-TOF GmbH, Münster, Germany) equipped with bismuth and $\mathrm{C}_{60}$ cluster ion sources. Before analysis, samples were ultrasonicated in ethanol (99\%) for $5 \mathrm{~min}$ (3 times), followed by ELGA/Milli$\mathrm{Q}$ water (Tremedic AB) for 15 minutes. Then, samples were dried in a flow of $\mathrm{N}_{2}$ gas before analysis. Mass spectra of positive and negative secondary ions were measured from two areas of $100 \times 100 \mu \mathrm{m}^{2}$ (divided into 128 pixels) ${ }^{2}$ on each sample, with a data acquisition time of $50{\mathrm{~s} . \mathrm{Bi}_{3}}^{+}(25 \mathrm{keV})$ was used as primary ions, with a target current of $0.1 \mathrm{pA}$. Each spectrum was calibrated by assigning theoretical masses to known peaks. For depth profiles, the sample areas were sputtered with a beam of $\mathrm{C}_{60}{ }^{+}$ions $(10 \mathrm{keV}$, target current $0.4-0.5 \mathrm{nA}$, area $250 \times 250 \mu \mathrm{m}^{2}$ ). The depth profiles (positive mode) were done with cycles of sputtering for $5 \mathrm{~s}$, followed by data acquisition for $10 \mathrm{~s}$ (same area and pixels as above) with a pause of $1 \mathrm{~s}$. The depth profile measurements were continued until the $\mathrm{TiO}_{2}$-related peak (main $\mathrm{TiO}^{+}$at $\mathrm{m} / \mathrm{z}$ 64) intensity had leveled out in the metal (after 250-300 s of total $\mathrm{C}_{60}{ }^{+}$sputtering). The thickness of the oxide layer measured in the depth profiles was calculated from the time required to sputter through the oxide layer. Conversion of the sputter time to depth was done by calibration of the sputter rate of $\mathrm{TiO}_{2}$ on a standard titanium plate with a known oxide thickness. 


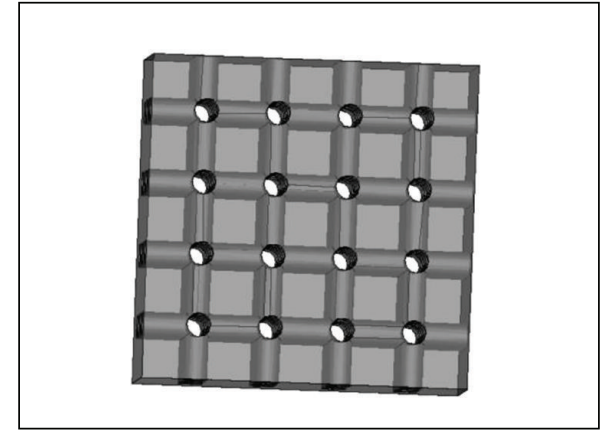

(a)

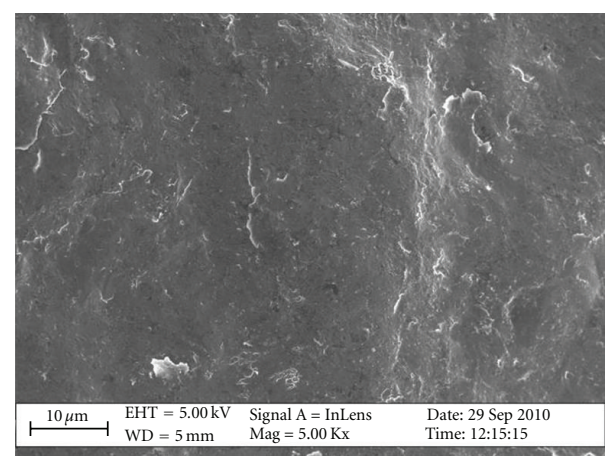

(c)

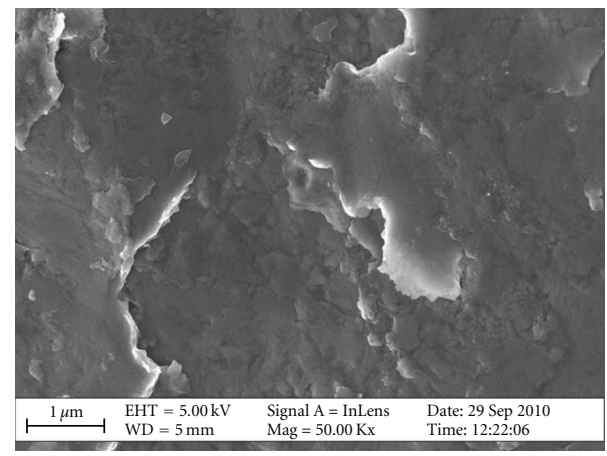

(d)

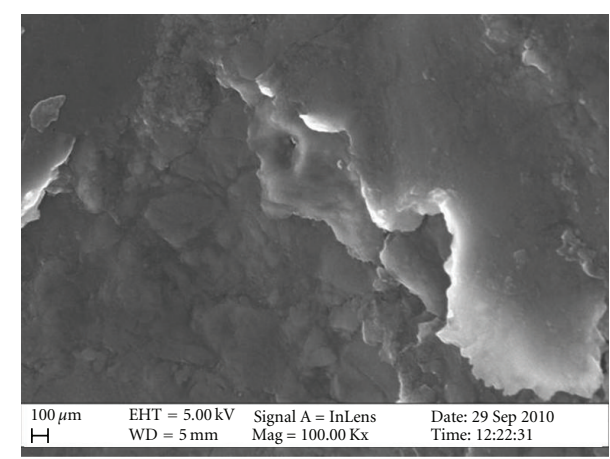

(e)

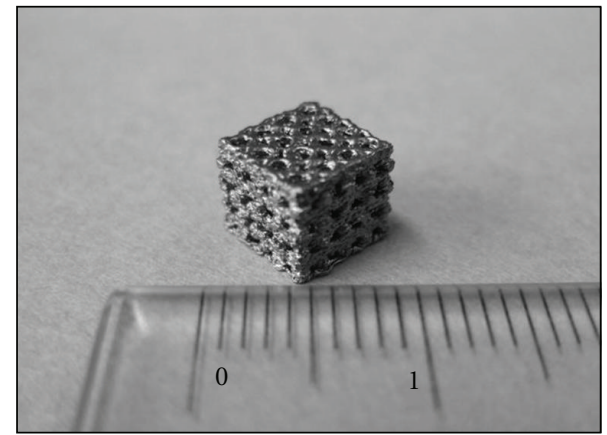

(b)

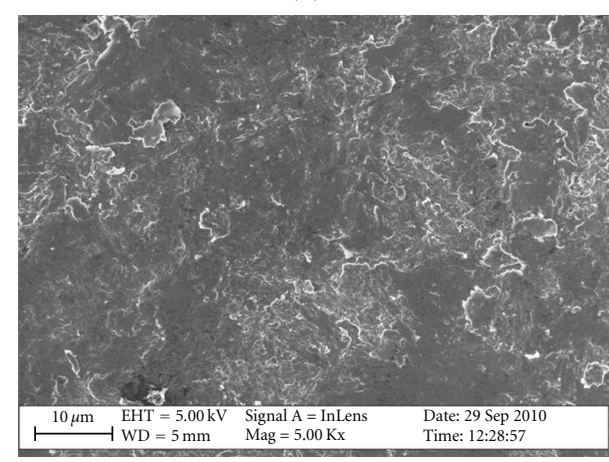

(f)

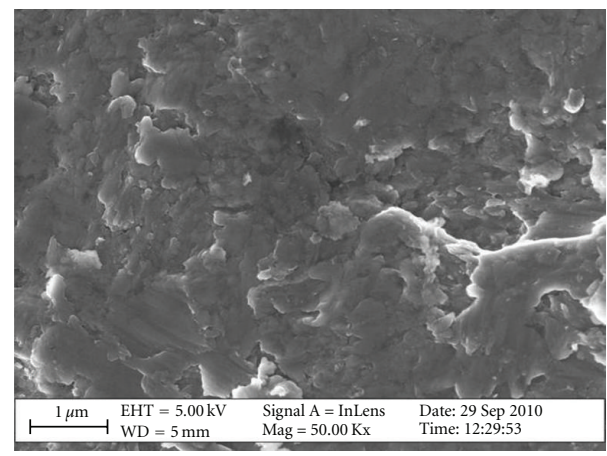

(g)

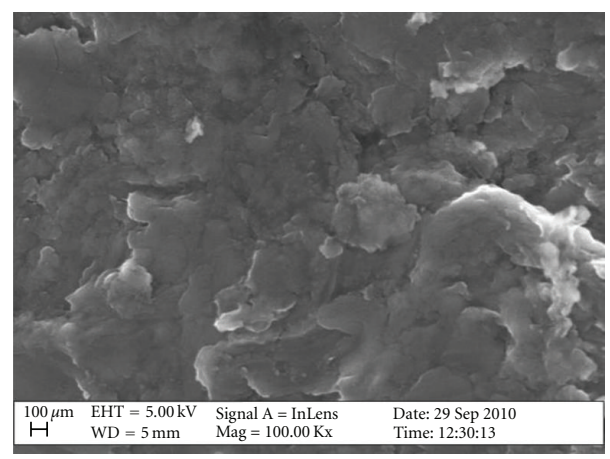

(h)

FIgUre 1: (a) CAD model used for the EBM-fabrication of cp-Ti and Ti6Al4V scaffolds. (b) A photograph showing the scaffolds used in the present study. (c-h) SEM images showing the surface topography of $\mathrm{cp}-\mathrm{Ti}(\mathrm{c}-\mathrm{e})$ and Ti6Al4V $(\mathrm{f}-\mathrm{h})$ scaffolds at increasing magnifications; scale bar $=10 \mu \mathrm{m}, 1 \mu \mathrm{m}$, and $100 \mathrm{~nm}$, respectively. 
2.4. Cell Derivation and Expansion. hES-MPs were provided by Cellartis (Gothenburg, SE; http://www.cellartis.com/). The hES-MPs were derived from an undifferentiated hES cell line (SA002.5), and their derivation and characterization has been described earlier [36]. Briefly, undifferentiated hES cells were removed from the supporting feeder layer and plated onto $0.1 \%$ porcine gelatin-coated cell culture dishes (BD Falcon/BD Biosciences, Bedford, MA, USA) in medium consisting of DMEM-HG (PAA Laboratories, Linz, Austria) supplemented with 1\% Penicillin-Streptomycin (PEST, PAA Laboratories), L-glutamine (2 mM, Gibco, Paisley, UK), 10\% fetal bovine serum (FBS, Gibco), and $10 \mathrm{ng} / \mathrm{mL}$ bFGF (Invitrogen, Paisley, United Kingdom). To initiate the derivation of hES-MPs, the hESCs were enzymatically passaged as a single cell suspension using TrypLE Select (Invitrogen) and were subsequently plated onto gelatin-coated culture dishes. This procedure was repeated every 7 days until the cell population became homogeneous for a mesenchymal morphology. Following the initial derivation steps, the hES-MPs were cultured in uncoated tissue culture flasks (BD Falcon/BD Biosciences) in a humidified atmosphere at $37^{\circ} \mathrm{C}$ and $5 \% \mathrm{CO}_{2}$ and enzymatically passaged with TrypLE Select every 7 days.

Cells were expanded in the medium described above. Medium was changed every 3-4 days and cells were passaged when reaching $80 \%$ confluence. Cells were cultured at $37^{\circ} \mathrm{C}$ in $5 \% \mathrm{CO}_{2}$.

2.5. Cell Seeding. A centrifugal seeding technique was used in order to increase cell penetration and attachment across the scaffolds [39]. Scaffolds were placed in round-bottom tube, and $1 \mathrm{~mL}$ of cell suspension $\left(10^{6} \mathrm{cell} / \mathrm{mL}\right)$ was added per each scaffold. Tubes containing the cell-scaffold constructs were then spun at $1200 \mathrm{rpm}$ for $5 \mathrm{~min}$. After centrifugation, unattached cells were resuspended and seeded again. The centrifugation procedure was repeated 5 times. Cell/scaffold constructs were finally incubated at $37^{\circ} \mathrm{C}$ in $5 \% \mathrm{CO}_{2}$ for $24 \mathrm{~h}$.

2.6. Osteogenic Stimulation. hES-MPs were cultured under osteogenic conditions for 6 weeks. Briefly, cell/scaffold constructs were cultured in $15 \mathrm{~mL}$ tubes (Falcon, BD, Franklin Lakes, NJ, USA) in DMEM-LG (PAA Laboratories) supplemented with $1 \%$ PEST, L-glutamine (2 mM), 10\% FBS, L-ascorbic acid $\left(4.5 \times 10^{-5} \mathrm{M}\right.$; Sigma-Aldrich, St. Louis, MO, USA), dexamethasone ( $10^{-6} \mathrm{M}$; Sigma-Aldrich), and $\beta$-glycerophosphate $\left(2 \times 10^{-2} \mathrm{M}\right.$; Calbiochem, Darmstadt, Germany). Cell/scaffold constructs were incubated at $37^{\circ} \mathrm{C}$ in $5 \% \mathrm{CO}_{2}$. Medium was changed twice a week.

2.7. Cell Attachment and Distribution. Cell attachment across the scaffolds was investigated by scanning electron microscopy (SEM) 2 days after culture under osteogenic conditions. For SEM investigation, cell/scaffold constructs were rinsed twice in phosphate saline buffer (PBS) before adding them in a modified solution of Karnovsky fixative, consisting of a solution of sodium azide $(0.02 \%$; Fluka Biochemika GmbH, Buchs, Switzerland), paraformaldehyde (2\%; VWR International, Stockholm, Sweden) and glutaraldehyde
(2.5\%; Agar Scientific, Stansted, England) in sodium cacodylate buffer $(0.05 \mathrm{M}$; Agar Scientific). Then, cell/scaffold constructs were treated with a solution of $\mathrm{OsO}_{4}(1 \%$; Agar Scientific) in sodium-cacodylate buffer and stored at $4^{\circ} \mathrm{C}$ for $4 \mathrm{~h}$. After rinsing 5 times with distilled $\mathrm{H}_{2} \mathrm{O}$, samples were treated with hexamethyldisilazane (1\%; Fluka, Sigma) before adding again a solution of $\mathrm{OsO}_{4}(1 \%)$ in sodium cacodylate buffer $(0.1 \mathrm{M})$. After dehydration with ethanol of increasing concentration, samples were treated twice $(10 \mathrm{~min})$ with a solution of hexamethyldisilazane (1\%; Fluka, Sigma) and dried overnight. For analysis, samples were sputter coated (EMITECH K550X; EMITECH, Kent, UK) with palladium for $2 \mathrm{~min}$ at $25 \mathrm{~mA}$ before SEM examination. The SEM analysis was performed as described above.

2.8. DNA Content. In order to compare cell proliferation across the cp-Ti a and Ti6Al4V scaffolds, the total DNA content was measured after 1 and 2 weeks of culture under osteogenic conditions. Briefly, samples were rinsed twice with PBS and then treated with a solution of papain (SigmaAldrich) for about $5 \mathrm{~min}$. Samples were then placed in oven at $60^{\circ} \mathrm{C}$ for $1 \mathrm{~h}$ for homogenization. Afterwards, lysates were collected, placed in Eppendorf tubes, and left in oven at $60^{\circ} \mathrm{C}$ overnight to allow drying. Samples were later dissolved in $200 \mu \mathrm{L}$ of phosphate buffer containing EDTA (PBE; $5 \mathrm{mM}$, $\mathrm{pH}$ 7.5) and stained with a solution of Hoechst 33258 $\left(3.7 \times 10^{-8} \mathrm{M}\right.$; Sigma-Aldrich $)$ in PBE buffer. After an incubation period of $10 \mathrm{~min}$ in the dark, samples were excited by ultraviolet light at $360 \mathrm{~nm}$ and emission read at $460 \mathrm{~nm}$ in a SPECTRAmax GEMININI (Medical Devices, Inc., Sunnyvale, CA, USA) microplate reader using the Softmax Pro software (Medical Devices, Inc.). A standard curve consisting of serially diluted calf thymus DNA was run in the same microplate.

2.9. Flow Cytometry Analysis. In order to estimate the rate of cellular death for cells seeded both onto $\mathrm{cp}$-Ti and Ti6Al4V, samples were harvested after 5 days of culture under osteogenic conditions and cells analyzed using the FITC Annexin V Apoptosis Detection Kit I (Becton Dickinson, Franklin Lakes, NJ, USA). Briefly, cells were trypsinated for about $10 \mathrm{~min}$, washed twice with PBS, and resuspended in $1 \mathrm{X}$ binding buffer (Becton Dickinson) before staining. Cells were stained with $5 \mu \mathrm{L}$ of FITC Annexin V and $5 \mu \mathrm{L}$ of propidium iodide (PI) and incubated for $15 \mathrm{~min}$ at room temperature in the dark. Cells were analyzed by flow cytometry within $1 \mathrm{~h}$. All samples were analyzed using the FACS Aria flow cytometer (Becton Dickinson) using the FACS Diva software (Becton Dickinson).

2.10. Lactate Dehydrogenase Activity. In order to investigate the proportion of cellular death, the activity of lactate dehydrogenase $(\mathrm{LDH})$ released into the cell culture medium was measured weekly. Briefly, medium was collected and the LDH activity was analyzed using a Cytotoxicity Detection Kit. The LDH activity was determined in a coupled enzymatic reaction during which $\mathrm{NAD}^{+}$is reduced to NADH. The formation rate of NADH was measured at $340 \mathrm{~nm}$ and considered proportional to the catalytic activity of LDH. 
The analysis was performed at the accredited laboratory of Sahlgrenska University Hospital.

2.11. Quantitative Real-Rime PCR. In order to examine osteogenic differentiation, cells seeded onto cp-Ti and Ti6Al4V were analyzed by real-time (RT) PCR after 1 and 2 weeks of culture under osteogenic conditions. Cell-scaffold constructs were treated with a solution of RLT buffer, with addition of $1 \% \beta$-mercaptoethanol, and the lysate vortexed for one min. The lysate was later transferred directly into a QIAshredder spin column and centrifuged for 2 min. Total RNA from the samples was extracted using RNeasy Minikit (QIAGEN $\mathrm{GmbH}$, Hilden, Germany) according to the manufacturer's instructions. DNAse treatment was performed in order to eliminate any contamination from genomic DNA. Reverse transcription was carried out using iScript cDNA Synthesis Kit (Bio-Rad, Hercules, USA) in a $10 \mu \mathrm{L}$ reaction, according to the manufacturer's instructions. Design of primers for RUNX2, COL1A1, OPN, and OC was performed using the Primer3 web-based software [40]. Design parameters were adjusted to minimize formation of artifact products and to be able to use an annealing temperature in the PCR at about $60^{\circ} \mathrm{C}$. Primers were designed to yield short amplicons (preferably shorter than $200 \mathrm{bp}$ ) and to function well with SYBR Green I fluorescent dye for detection of the PCR products in real time. Primer sequences are available at TATAA Biocenter AB (http://www.tataa.com).

RT-PCR was performed in duplicates using the Mastercycler ep realplex (Eppendorf, Hamburg, Germany) in $20 \mu \mathrm{L}$ reactions. Cycling conditions were $95^{\circ} \mathrm{C}$ for $10 \mathrm{~min}$ followed by 45 cycles of $95^{\circ} \mathrm{C}$ for $20 \mathrm{~s}, 60^{\circ} \mathrm{C}$ for $20 \mathrm{~s}$, and $72^{\circ} \mathrm{C}$ for $20 \mathrm{~s}$. The fluorescence was read at the end of the $72^{\circ} \mathrm{C}$ step. Melting curves were recorded after the run by stepwise temperature increase $\left(1^{\circ} \mathrm{C} / 5 \mathrm{~s}\right)$ from 65 to $95^{\circ} \mathrm{C}$.

Quantities of target genes were presented as normalized to the number of cell using the expression of $18 \mathrm{~S}$ ribosomal subunit. Normalized relative quantities were calculated using the delta Ct method and 90\% PCR efficiency $\left(\mathrm{k}^{*} 1.9^{\Delta \mathrm{ct}}\right)$.

2.12. Alkaline Phosphatase Activity. After 10 days of culture under osteogenic conditions, the alkaline phosphatase (ALP) activity was measured following the lysis of the cells using MPER (Fisher Scientific, Gothenburg, Sweden). ALP activity was assayed by using p-nitrophenylphosphate as substrate. The quantity (in alkaline solution) of p-nitrophenol produced, which exhibits an absorbance maximum at $405 \mathrm{~nm}$, was considered directly proportional to the alkaline phosphatase activity. The analysis was performed at the accredited laboratory of Sahlgrenska University Hospital.

2.13. Histology. After 6 weeks of culture cell-scaffold, constructs were plastic embedded and ground sectioned for histological analysis. Briefly, cp-Ti and Ti6Al4V constructs were rinsed twice with PBS and fixated in $4 \%$ formaldehyde for $4 \mathrm{~h}$ at $3-5^{\circ} \mathrm{C}$. After fixation, constructs were rinsed three times with ELGA/Milli-Q water (Tremedic AB) on an orbital shaker. After dehydration with ethanol of increasing concentration, the constructs were embedded in plastic resin
(LR White, the London Resin Co. Ltd., Hampshire, UK) and hardened on ice. Samples were cut using the Exakt cuttingGrinding equipment as described elsewhere [41]. The final section was approximately $50-60 \mu \mathrm{m}$ thick. The scaffolds with surrounding cells were stained with toluidine blue staining before cover glass mounting, and observed using light microscopy (Eclipse E600; Nikon, Japan).

2.14. Statistical Analysis. Results are expressed as means and standard deviations. Three samples were used per each analysis. Differences were determined by the nonparametric Mann-Whitney test for independent samples using the SPSS Statistics 17.0 software. For all the analyses, a value of $P \leq$ 0.05 was considered as significant difference.

\section{Results}

3.1. Topography and Surface Chemical Composition. In Figure 1, SEM images showing the topography of cp-Ti (c-e) and Ti6Al4V ( $\mathrm{f}-\mathrm{h})$ scaffolds at different magnification are shown. While slight differences were observed in surface roughness at the micron scale level between scaffolds of $\mathrm{cp}$ - Ti (Figures 1(c) and 1(d)) and Ti6Al4V (Figures 1(f) and 1(g)), both materials displayed a similar topography, with relatively flat areas and areas with flakes and protrusions as seen in the high-magnification SEM images displayed in Figures 1(e) and $1(\mathrm{~h})$, respectively.

ToF-SIMS spectra from the surface of the cp-Ti and Ti6Al4V samples were similar (Figure 2(a)), indicating no major differences in surface chemical composition between the two materials. The spectra were dominated by organic fragment ions of the type $\mathrm{C}_{\mathrm{x}} \mathrm{H}_{\mathrm{y}}{ }^{+}$and $\mathrm{C}_{\mathrm{x}} \mathrm{H}_{\mathrm{y}} \mathrm{O}^{+}$(presumably due to adsorbed organic molecules from the ambient) and signals that can be attributed to $\mathrm{TiO}_{2}$ (e.g., $\mathrm{Ti}^{+}, \mathrm{TiO}^{+}, \mathrm{Ti}_{2} \mathrm{O}^{+}$, $\mathrm{Ti}_{2} \mathrm{O}_{3}{ }^{+}$). However, the alloy-related ion peaks, specifically $\mathrm{Al}$ (blue) and V (green), were higher in the Ti6Al4V samples compared to the cp-Ti samples as shown in Figures 2(b) and 2 (c), respectively. On the other hand, titanium-related peaks were slightly higher in the cp-Ti samples than the alloyed samples as shown in Figures 2(d) and 2(e). Spectra measured after removal of the oxide layer were dominated by Ti signals. In addition, the alloys showed clear signals from the alloy elements $\mathrm{Al}$ and $\mathrm{V}$.

TOF-SIMS analysis of the scaffold surface showed no significant differences in oxide layer thickness between the cp-Ti and Ti6Al4V scaffolds, resulting in an average thickness of $24 \mathrm{~nm}$ for both cp-Ti and Ti6Al4V scaffolds (Table 1).

3.2. Cell Attachment. Cell attachment and distribution across the scaffolds were assessed by SEM investigation 2 days after seeding. Figure 3 demonstrates that both $\mathrm{cp}-$ Ti (Figures 3(a)-3(c)) and Ti6Al4V (Figures 3(d)-3(f)) constructs displayed a homogenous distribution of cells across the scaffold (Figures 3(a) and 3(b) resp.), with a dense layer of cells covering the entire surface. Cells displayed a flat morphology with cellular protrusions extending from the cellular periphery both on cp-Ti (Figures 3(a) and 3(b)) and Ti6Al4V (Figures 3(d) and 3(e)) scaffolds. In proximity 

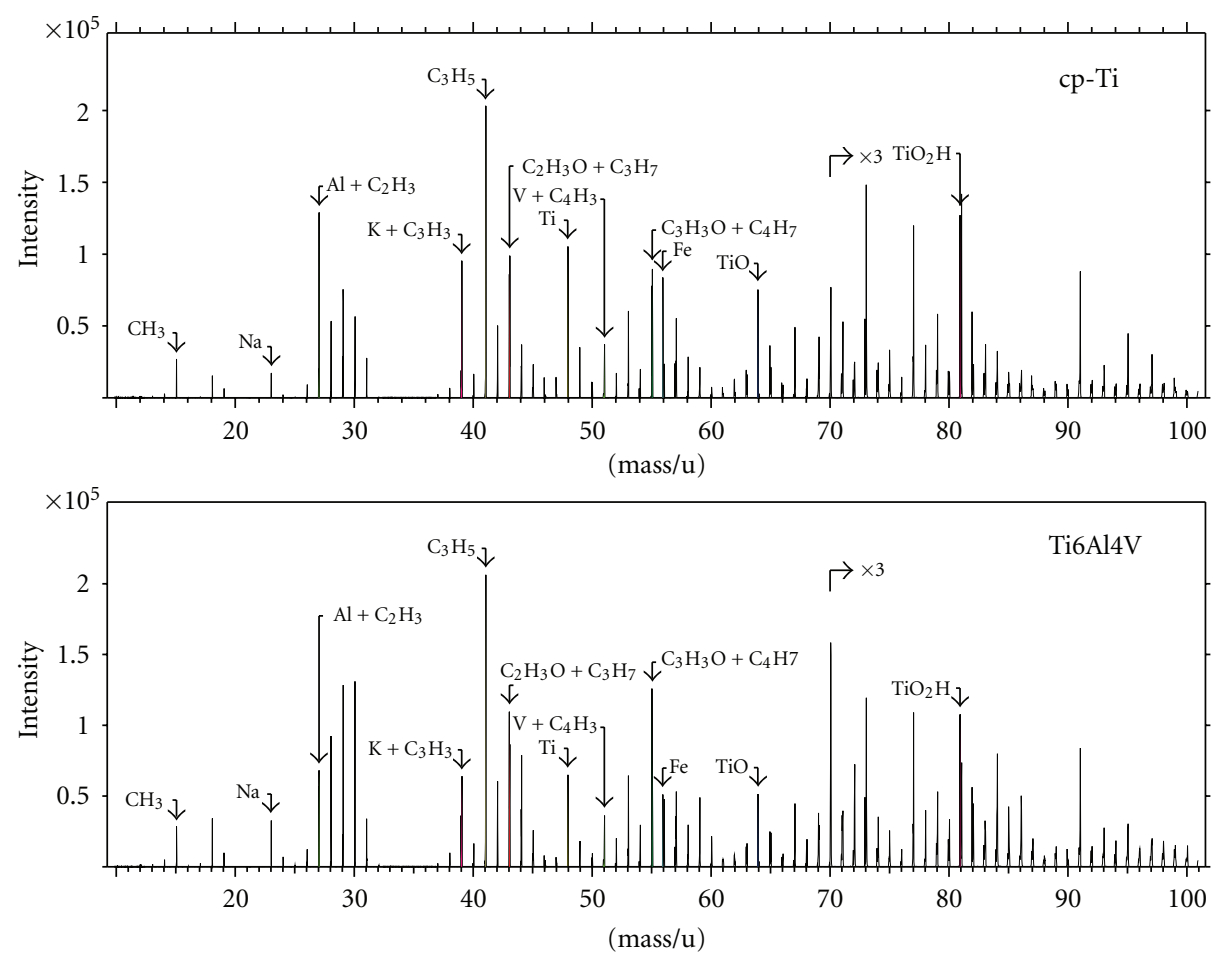

(a)

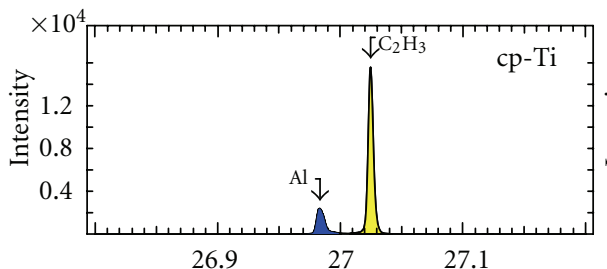

(u)

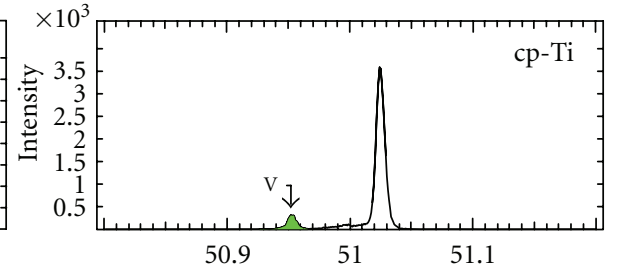

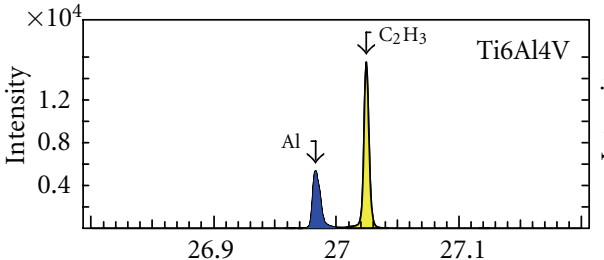

(u)

(b)

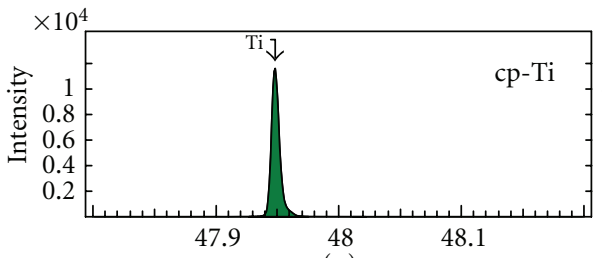

(u)

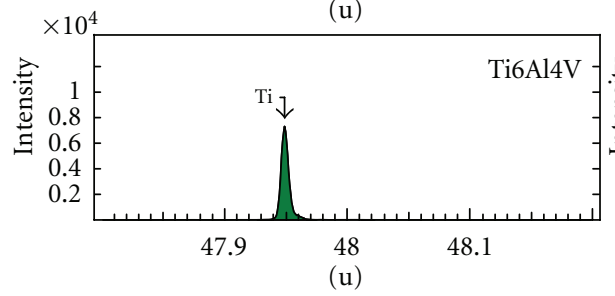

(d)

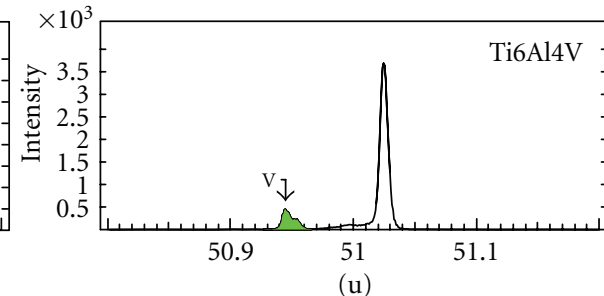

(c)

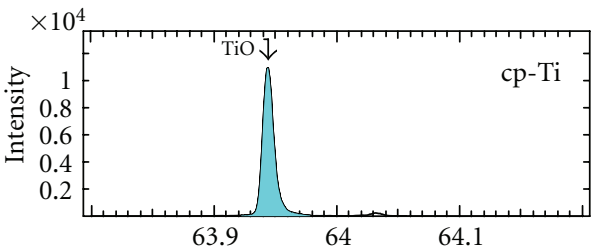

(u)

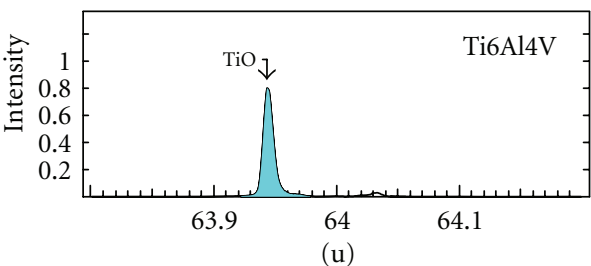

(e)

FIGURE 2: (a) TOF-SIMS spectra showing the elemental surface compositions of the cp-Ti and Ti6Al4V scaffolds. Enlargements of the spectra displaying the $\mathrm{Al}^{+}(\mathrm{b}), \mathrm{V}^{+}(\mathrm{c}), \mathrm{Ti}^{+}(\mathrm{d})$, and $\mathrm{TiO}^{+}$(e) peaks. 


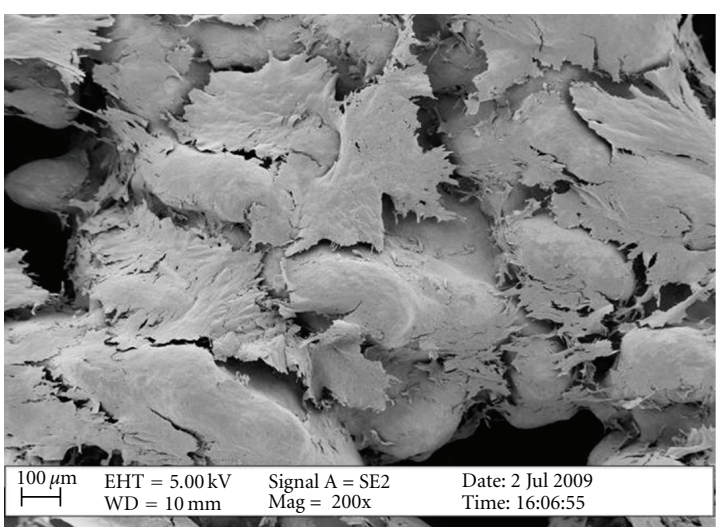

(a)

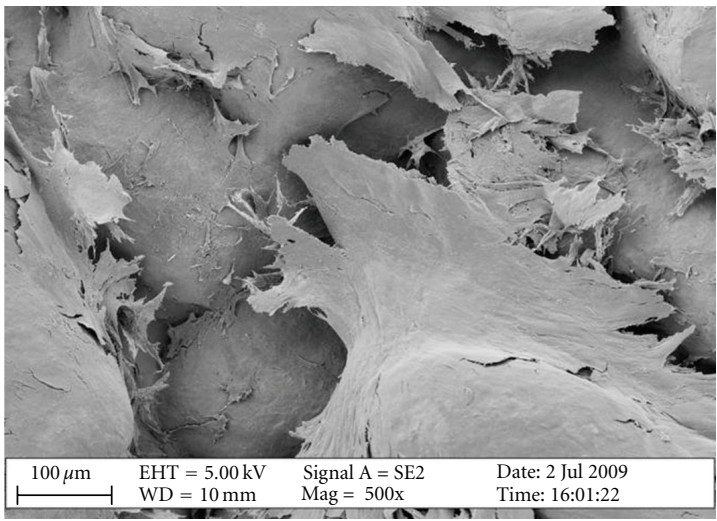

(b)

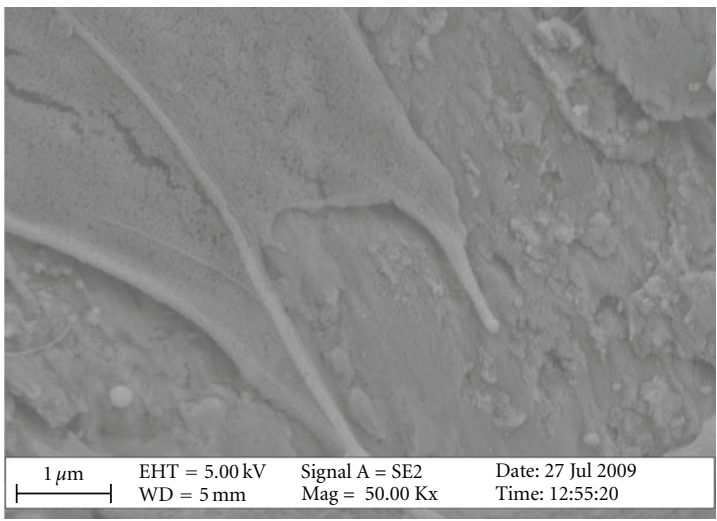

(c)

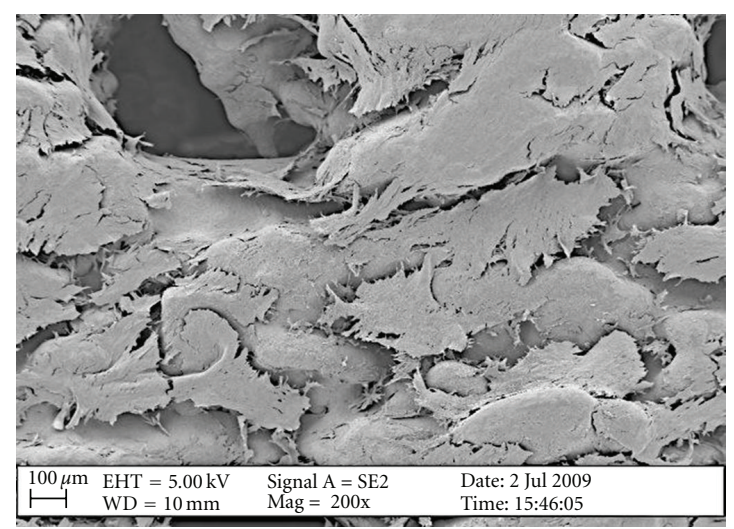

(d)

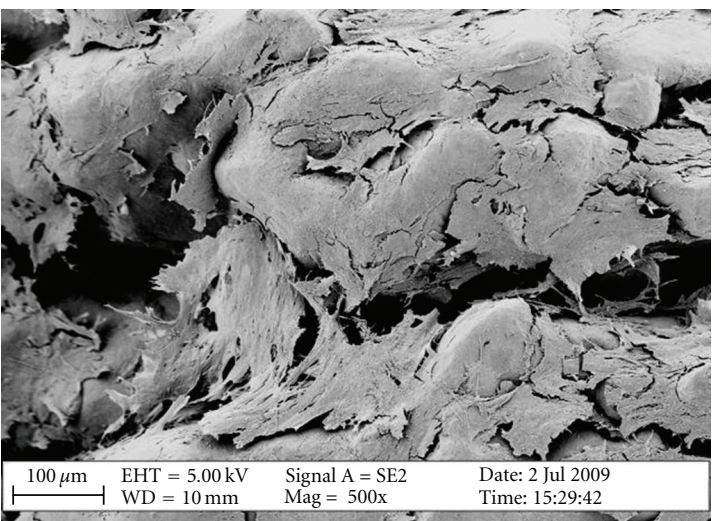

(e)

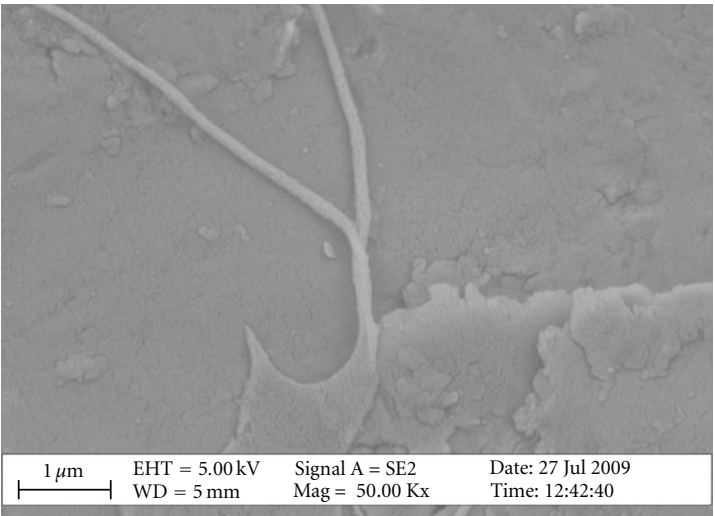

(f)

FIgURE 3: SEM images showing hES-MPs morphology and distribution across the cp-Ti (a-d) and Ti6Al4V (e-h) scaffolds; scale bar = $200 \mu \mathrm{m}(\mathrm{a}, \mathrm{b}, \mathrm{d}$, and $\mathrm{f})$ and $1 \mu \mathrm{m}$ (c and f).

of the scaffold pores, cells appeared to follow the curvature of the surface and stretch out inside the pore both when seeded on cp-Ti (Figure 3(b)) and Ti6Al4V (Figure 3(e)) scaffolds. Figures 3(c) and 3(f) show details of cellular filopodia interacting with the underlying surface for $\mathrm{cp}-\mathrm{Ti}$ and Ti6Al4V scaffolds, respectively.

3.3. Cell Proliferation and Viability. The effect of cp-Ti and Ti6Al4V scaffolds on cell proliferation was investigated by measuring the DNA content after 1 and 2 weeks of culture. In Figure 4(a), the DNA content for $\mathrm{cp}-\mathrm{Ti}$ and Ti6Al4V constructs is shown. No significant differences were observed between the two constructs after 1 and 2 weeks of culture.

Cell viability was assessed by flow cytometry after 1 week of culture and by measuring the LDH activity weekly along the entire duration of the experiment. In Figures 4(b) and $4(\mathrm{c})$, the proportion of viable $(\mathrm{Q} 1)$, apoptotic $(\mathrm{Q} 2, \mathrm{Q} 3)$, and dead (Q4) cells is shown for cp-Ti and Ti6Al4V constructs, respectively. For both scaffolds, a similar pattern was observed, with $69 \%$ and $71 \%$ of the total counted cells found to be viable for $\mathrm{cp}-\mathrm{Ti}$ and Ti6Al4V scaffolds, respectively. LDH results displayed a similar pattern for both constructs 


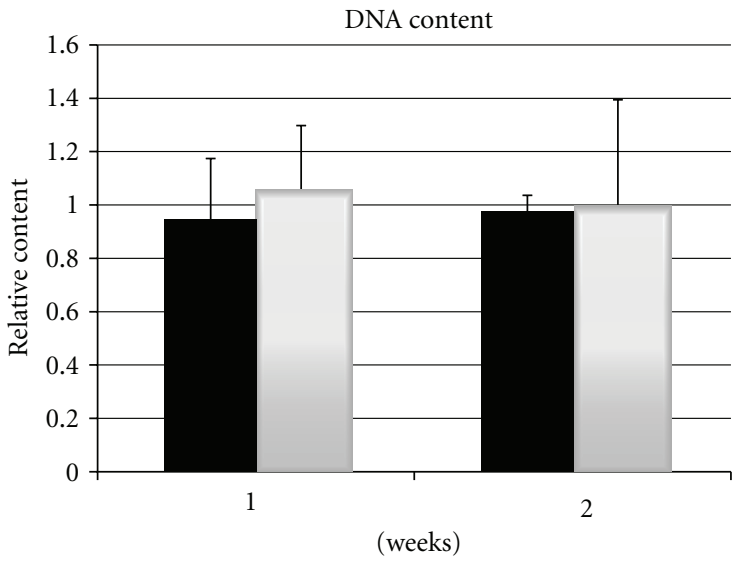

cp-Ti

- Ti6Al4V

(a)

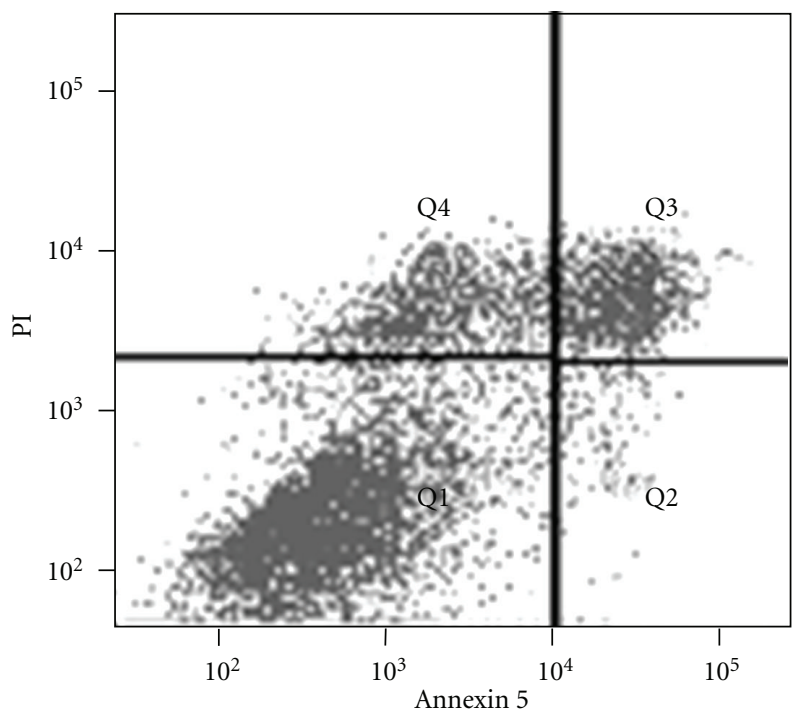

(b)

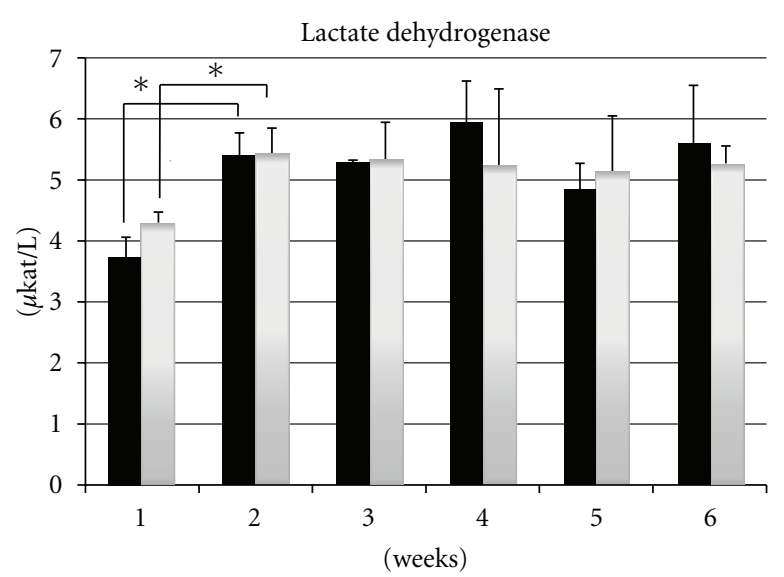

cp-Ti

Ti6Al4V

(d)

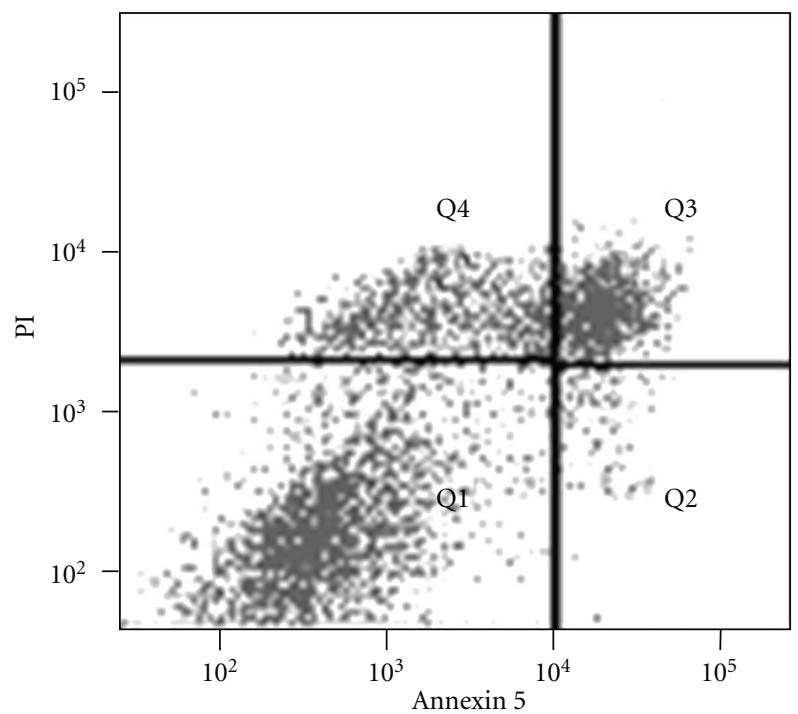

(c)

FIgure 4: (a) Histograms showing the content of DNA for both constructs after 1 and 2 weeks of culture. (b-c) Flow cytometry plots displaying the proportion of viable (Q1), apoptotic (Q2, Q3), and dead (Q4) cells are shown for cp-Ti (b) and Ti6Al4V (c) constructs. (d) Histograms showing the $\mathrm{LDH}$ activity for both constructs along the entire duration of the experiment. A value of $P<0.05$ was taken as a significant difference $(*)$.

as shown in Figure 4(d). After a significant increase in LDH activity detected after 2 weeks, no significant variations were found for the following time points investigated and between constructs of cp-Ti and Ti6Al4V.

3.4. Histology. Histological investigation was used to assess cell growth across the scaffolds. In Figure 7, toluidine-stained sections for both constructs of cp-Ti (Figures 7(a)-7(c)) and Ti6Al4V (Figures 7(d)-7(e)) are shown. hES-MPs grew uniformly on both scaffolds and formed cellular layers following the irregularities of the underlying material surface.

3.5. Osteogenic Differentiation. The effect of material surface composition on osteogenic differentiation was investigated by real-time PCR and ALP activity measurements. In Figure 5, the expression of RUNX2,COL1A1, OPN, and OC is shown. Per each gene the higher expression value was used as baseline. Both constructs of cp-Ti and Ti6Al4V displayed increased expression of RUNX2 after 2 week of culture (Figure 5(a)), although the observed increase was found to be significant only for constructs of $\mathrm{cp}$-Ti. No differences were observed between the two types of constructs. On the other hand, COL1A1 displayed a significant decrease in expression after 2 weeks for both constructs (Figure 5(b)), but no differences were observed when hES-MPs were seeded on cp-Ti or Ti6Al4V scaffolds. Figure 5(c) shows that the expression of OPN displays an increase after 2 weeks for both constructs. However, the observed increase was found 
RUNX2

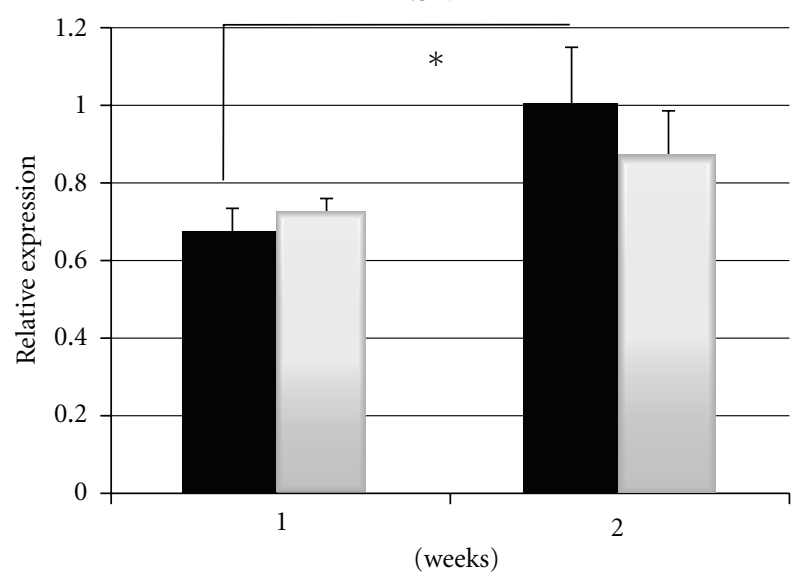

$\mathrm{cp}-\mathrm{Ti}$

$\square$ Ti6Al4V

(a)

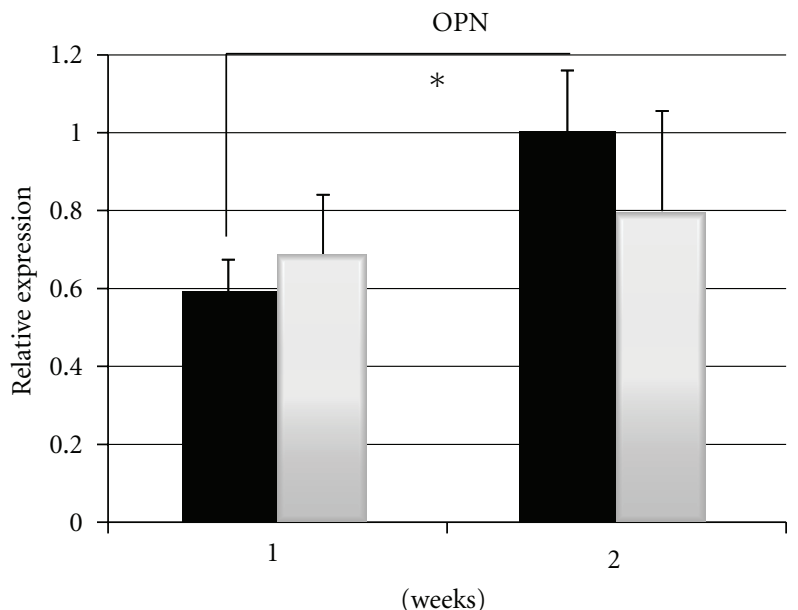

$\mathrm{cp}-\mathrm{Ti}$

Ti6Al4V

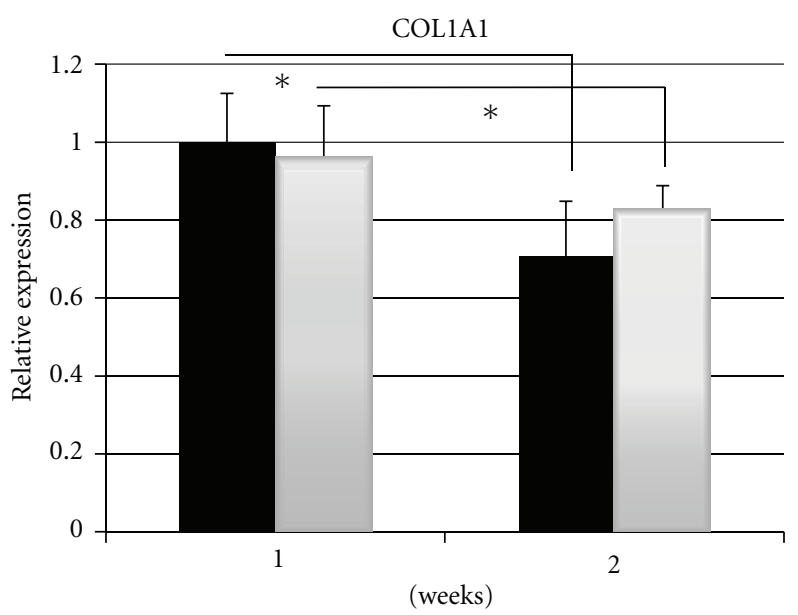

$\mathrm{cp}-\mathrm{Ti}$

Ti6Al4V

(b)

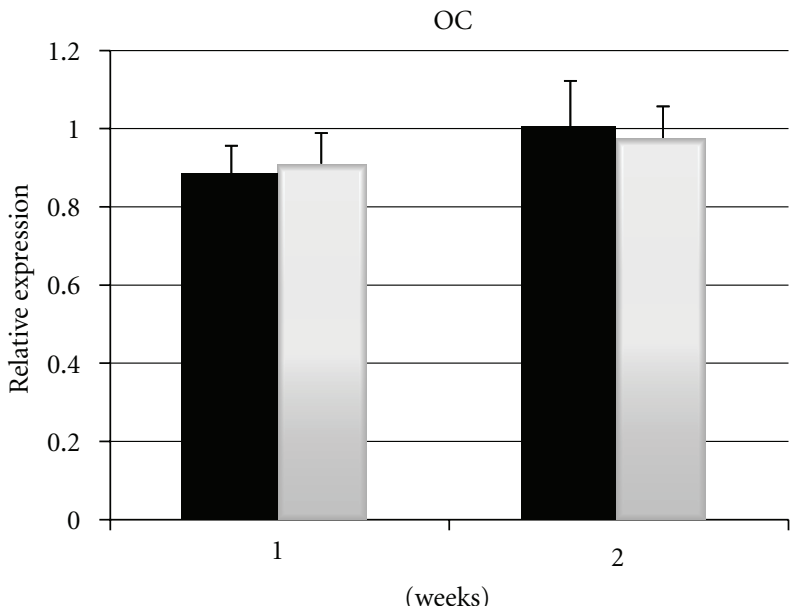

cp-Ti

Ti6Al4V

(c)

(d)

FIgURE 5: Real-time PCR results showing the expression of RUNX2, COL1A1, OPN, and OC after 1 and 2 weeks of culture for both constructs. Results are presented as relative expression values. A value of $P<0.05$ was taken as significant difference $\left(^{*}\right)$.

to be significant only for $\mathrm{cp}$-Ti constructs. No variations were observed in the expression of $O C$ between weeks 1 and 2, and between constructs of cp-Ti and Ti6Al4V (Figure 5(d)). Figure 6 shows the ALP activity data after 10 days of culture. The data demonstrated similar activity for both constructs of cp-Ti and Ti6Al4V.

\section{Discussion}

Free-form fabrication of implantable devices is emerging as an attractive technique for the production of $3 \mathrm{D}$ complex biomaterials for personalized applications in skeletal engineering. EBM has recently been used to fabricate cp-Ti and Ti6Al4V implants with excellent material properties [19, 42, 43 ] and has the ability to provide geometrical features, which support bone ingrowth and ensure a stable osseointegration
[20]. By varying the size of the pores and struts, EBM allows the modulation of device porosity and tailoring of optimal mechanical properties to meet specific requirements in different applications. An interesting concept is to interface biomaterials with stem cells in order to speed up the regeneration process and/or achieve better osseointegration of the implants, especially in situations characterized by poor bone quality or otherwise compromised regenerative capacity [44]. hMSCs are experimentally relevant cells but manifest important limitations for the large-scale production of cells, especially considering the limited proliferative potential and loss of functionality following in vitro expansion [33, 35, 37] or aging. On the other hand, hES-MPs are able to provide an unlimited source of functional osteoprogenitor cells for clinical applications. 


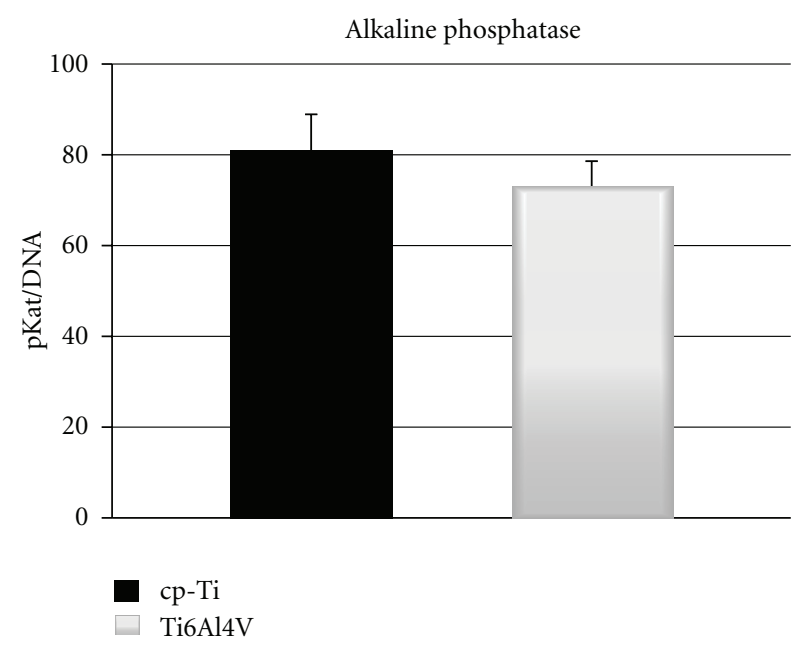

FIGURE 6: Histograms showing the ALP activity for both constructs after 10 days of culture.

The present study demonstrates that hES-MPs can be interfaced with EBM-fabricated cp-Ti and Ti6Al4V under in vitro conditions and may be successfully used in the design of third-generation biomaterials for skeletal engineering applications. Soon after seeding, hES-MPs formed a dense layer of cells in tight contact with the geometrical features of the cp-Ti and Ti6Al4V scaffolds, both in an orientation parallel and perpendicular to the built-in direction. When studying cell proliferation, no significant overtime increase in the content of DNA was detected for both constructs of cp-Ti and Ti6Al4V. It is recognized that increasing cell density arrests cell proliferation via the process of contact inhibition [45], and cell-cell interaction and communication are essential events for tissue formation [46]. Moreover, upon cell differentiation, the expression of genes involved in proliferation has been reported to be downregulated, indicating that a proliferation/differentiation switch exists [47]. In this perspective, especially considering the high proliferative potential of hES-MPs [35], the formation of a dense layer of cells, as demonstrated by SEM investigation after 2 days of culture, it is likely to explain the DNA content results observed. A similar proliferation/differentiation switch occurring at an early stage of ex vivo culture may represent an advantageous condition for a clinical use of the cell/scaffold constructs used in this study. On the other hand, after an initial period of high proliferative state, a stable balance between cell proliferation and cell death may have been reached, as previously observed in our laboratory. For example, flow cytometry data reported in the present study resulted in a cellular live/dead ratio of about 70/30 after the first week of culture for both constructs of cp$\mathrm{Ti}$ and Ti6Al4V, indicating that under osteogenic condtions cell death is an ongoing process, with possible biological importance during cell differentiation. In this regard, Lynch et al. reported evidence that cells undergo programmed cell death upon osteogenic differentiation in vitro [48]. However, when studying the LDH activity, a significant increase was observed between the first and second weeks of culture for
TABLE 1: The calculated oxide thicknesses for the cp-Ti and Ti6Al4V scaffolds, showing the mean value and standard deviation.

\begin{tabular}{lc}
\hline & Oxide thickness \\
Material & Th $(\mathrm{nm})$ \\
\hline cp-Ti 1 & 26.3 \\
cp-Ti 2 & 24.2 \\
cp-Ti 3 & 23.0 \\
cp-Ti 4 & 24.1 \\
\hline AVERAGE & 24.4 \\
\hline STDEV & 1.4 \\
\hline Ti6Al4V 1 & 30.0 \\
Ti6Al4V 2 & 22.1 \\
Ti6Al4V 3 & 23.7 \\
Ti6Al4V 4 & 21.8 \\
\hline AVERAGE & 24.4 \\
\hline STDEV & 3.8 \\
\hline
\end{tabular}

both constructs of $\mathrm{cp}$-Ti and Ti6Al4V, which possibly reflects an increased number of total cells and, as consequence, an increased number of cells undergoing cell death. The observed results are not in accordance with DNA content data suggesting that, although cell proliferation was ongoing between the first and second weeks of culture, technical limitations in DNA extraction may account for the discrepancy observed between the DNA content and LDH activity results. In a different fashion, cell viability may decrease over time, as reported by Muller et al. after seeding SAOS2 cells on cp-Ti porous scaffolds [49]. Interestingly, the LDH activity data showed that, after the first 2 weeks, the cellular live/dead ratio became stable until the sixth week of culture and was not influenced by the type of material used. The finding excludes any short-term cytotoxic effect associated with the presence of vanadium within the Ti6Al4V alloy. The histological analysis corroborates these other results, showing similar pattern of cells surrounding both constructs of cp-Ti and Ti6Al4V. Taken together, the above data suggests a similar influence of both materials on hES-MPs. However, it is clear that additional studies, both in vitro and in vivo, are fundamental to fully assess the effect of the investigated materials on hES-MPs.

At the implant site, circulating progenitor cells migrate, adhere and differentiate into functional osteoblasts, eventually favoring bone tissue formation and healing [24]. In this view, it is important to investigate whether the materials used in this study influence the expression of genes involved in osteogenic differentiation. In our study, the expression level of RUNX2, which is a transcriptional activator of osteoblastic differentiation [50], displayed an increase after 2 weeks of culture for both cp-Ti and Ti6Al4V scaffolds. The observed profiles do not correspond to those observed during our previous 2-dimensional studies, in which hES-MPs were characterized by a general decrease in RUNX2 expression at week 2, indicating that cells may respond differently when cultured under 3D conditions [51]. On the other hand, the material composition and topography of the scaffolds used 


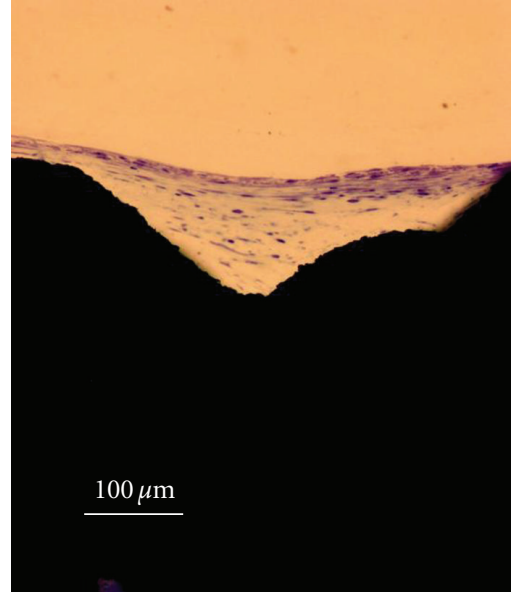

(a)

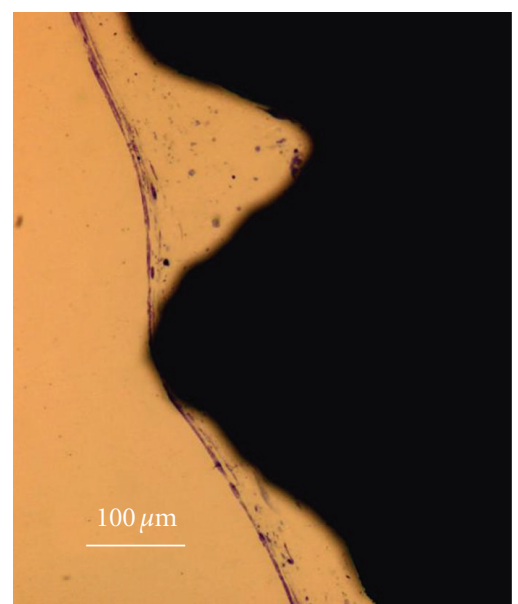

(b)

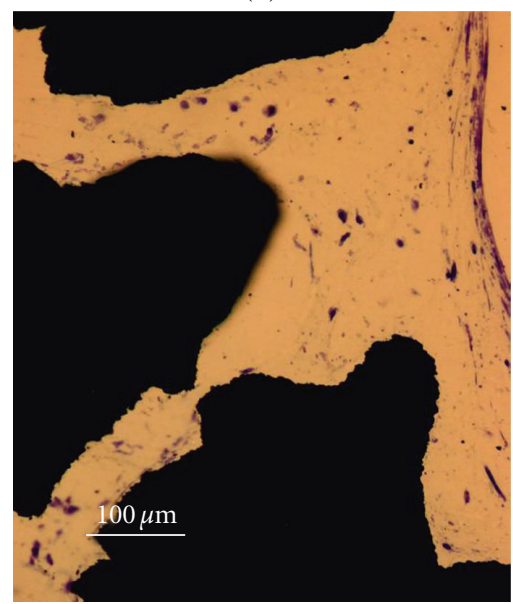

(c)

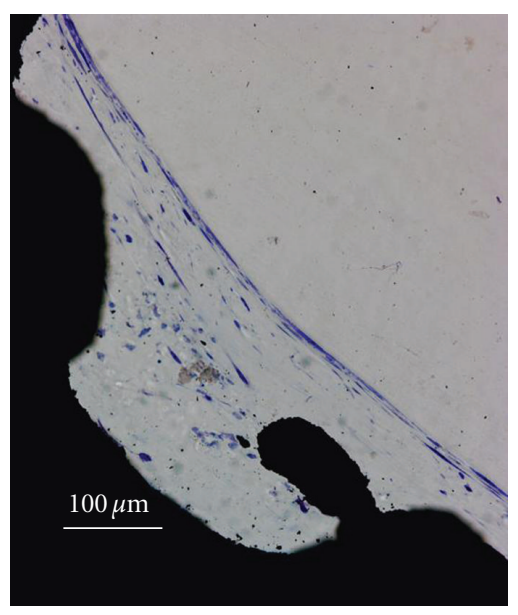

(d)

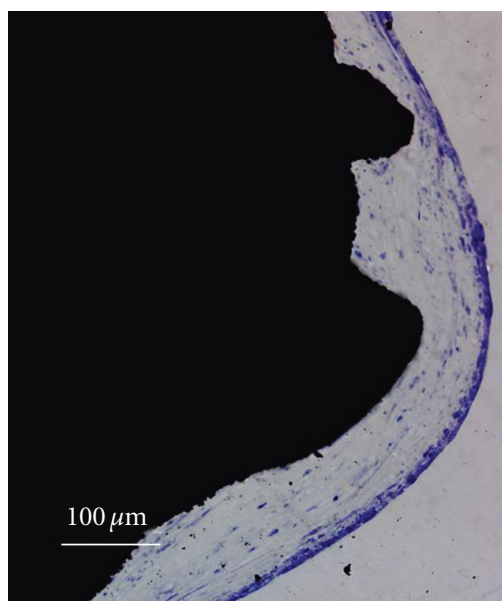

(e)

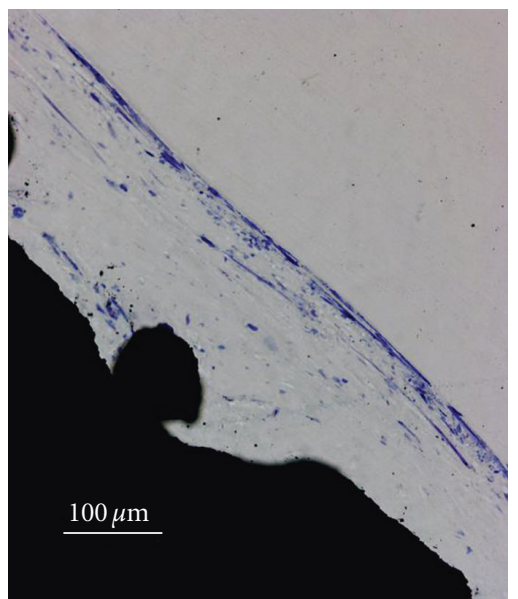

(f)

FIgURE 7: Histological micrographs of $\mathrm{cp}-\mathrm{Ti}(\mathrm{a}-\mathrm{c})$ and Ti6Al4V $(\mathrm{d}-\mathrm{f})$ constructs stained with toluidine blue; scale bar $=100 \mu \mathrm{m}$.

may play a synergistic effect in affecting gene expression and promoting osteogenic differentiation. A similar trend was observed for genes whose expression is recognized to be under the control of RUNX2 [52], such as OPN and $O C$, further supporting the idea that both scaffolds used in the present study possess osteoconductive properties [53].
On the contrary, COL1A1 displayed a significant decrease in expression for both constructs of cp-Ti and Ti6Al4V, highlighting the complex biology underlying gene expression, as well as the possibility that additional components control its regulation. In this regard, Tadic et al. demonstrated that Dlx5 played a role in regulating the expression of COL1A1 
into chick calvarial periosteal cells [54]. A similar decrease in COL1A1 expression was reported by Bedi et al. after culturing human fetal osteoblast on Ti6Al4V scaffolds [55]. Interestingly, for all genes investigated, the expression profile observed was similar when hES-MPs were interfaced to $\mathrm{cp}$ $\mathrm{Ti}$ and Ti6Al4V. In a similar fashion, when studying the activity of ALP, which is recognized to play a central role in osteogenesis and mineralization of the extracellular matrix $[56,57]$, no differences were observed between the two scaffold materials.

Altogether, the data reported in this study demonstrate the potential of hES-MPs to be interfaced to EBM-fabricated scaffolds. Displaying different chemical composition but similar surface properties with respect to topography, oxide thickness and composition, EBM-fabricated cp-Ti and Ti6Al4V scaffolds supported cell attachment and growth, and did not seem to alter the expression of genes involved in osteogenic differentiation and affect the activity of ALP. The materials did not exhibit any major adverse effect on hES-MPs behavior. Based on this observation, interfacing hES-MPs to EBM-fabricated scaffolds might represent an interesting alternative in the design of third-generation biomaterials for skeletal engineering applications. However, in vivo studies are fundamental to evaluate the true potential of hES-MPs to drive bone formation and promote implant osseointegration in clinical situations.

\section{Conclusions}

The ability to fabricate 3D metallic parts with complex geometrical features and tailored mechanical properties opens the possibility to design customized biomaterials that, in combination with patient-specific hES-MPs, hold the potential to promote bone formation and improve implant integration in clinical conditions characterized by poor bone quality.

\section{Acknowledgments}

The authors sincerely thank Birgitta Norlindh for helping with histology. They acknowledge BIOMATCELL VINN Excellence Center of Biomaterials and Cell Therapy, Region Västra Götaland, Swedish Research Council (K2009-52X09495-22-3 and 2005-7544), and JOIN (ed) T Marie Curie Action for the financial support of the study.

\section{References}

[1] C. M. Cowan, C. Soo, K. Ting, and B. Wu, "Evolving concepts in bone tissue engineering," Current Topics in Developmental Biology, vol. 66, pp. 239-285, 2005.

[2] K. Alvarez and H. Nakajima, "Metallic scaffolds for bone regeneration," Materials, vol. 2, pp. 790-832, 2009.

[3] J. B. Park and J. D. Bronzino, Biomaterials: Principles and Applications, CRC Press LLC, Boca Raton, Fla, USA, 2003.

[4] P. I. Branemark, "Osseointegration and its experimental background," The Journal of Prosthetic Dentistry, vol. 50, no. 3, pp. 399-410, 1983.

[5] A. Palmquist, F. Lindberg, L. Emanuelsson, R. Branemark, H. Engqvist, and P. Thomsen, "Morphological studies on machined implants of commercially pure titanium and titanium alloy (Ti6Al4V) in the rabbit," Journal of Biomedical Materials Research B, vol. 91, no. 1, pp. 309-319, 2009.

[6] A. Palmquist, F. Lindberg, L. Emanuelsson, R. Branemark, H. Engqvist, and P. Thomsen, "Biomechanical, histological, and ultrastructural analyses of laser micro- and nano-structured titanium alloy implants: a study in rabbit," Journal of Biomedical Materials Research A, vol. 92, no. 4, pp. 1476-1486, 2010.

[7] I. Gotman, "Characteristics of metals used in implants," Journal of Endourology, vol. 11, no. 6, pp. 383-389, 1997.

[8] K. Imai and M. Nakamura, "In vitro embryotoxicity testing of metals for dental use by differentiation of embryonic stem cell test," Congenital Anomalies, vol. 46, no. 1, pp. 34-38, 2006.

[9] Y. Okazaki, S. Rao, Y. Ito, and T. Tateishi, "Corrosion resistance, mechanical properties: corrosion fatigue strength and cytocompatibility of new Ti alloys without A1 and V," Biomaterials, vol. 19, no. 13, pp. 1197-1215, 1998.

[10] L. B. Zhou, H. T. Shang, L. S. He et al., "Accurate reconstruction of discontinuous mandible using a reverse engineering/computer-aided design/rapid prototyping technique: a preliminary clinical study," Journal of Oral and Maxillofacial Surgery, vol. 68, pp. 2115-2121, 2010.

[11] G. Ryan, A. Pandit, and D. P. Apatsidis, "Fabrication methods of porous metals for use in orthopaedic applications," Biomaterials, vol. 27, no. 13, pp. 2651-2670, 2006.

[12] A. Curodeau, E. Sachs, and S. Caldarise, "Design and fabrication of cast orthopedic implants with freeform surface textures from 3-D printed ceramic shell," Journal of Biomedical Materials Research, vol. 53, no. 5, pp. 525-535, 2000.

[13] G. E. Ryan, A. S. Pandit, and D. P. Apatsidis, "Porous titanium scaffolds fabricated using a rapid prototyping and powder metallurgy technique," Biomaterials, vol. 29, no. 27, pp. 36253635, 2008.

[14] J. P. Li, J. R. de Wijn, C. A. van Blitterswijk, and K. de Groot, "Porous Ti6Al4V scaffolds directly fabricated by 3D fibre deposition technique: effect of nozzle diameter," Journal of Materials Science: Materials in Medicine, vol. 16, no. 12, pp. 1159-1163, 2005.

[15] L. Mullen, R. C. Stamp, W. K. Brooks, E. Jones, and C. J. Sutcliffe, "Selective laser melting: a regular unit cell approach for the manufacture of porous, titanium, bone in-growth constructs, suitable for orthopedic applications," Journal of Biomedical Materials Research B, vol. 89, no. 2, pp. 325-334, 2009.

[16] I. V. Shishkovsky, L. T. Volova, M. V. Kuznetsov, Y. G. Morozov, and I. P. Parkin, "Porous biocompatible implants and tissue scaffolds synthesized by selective laser sintering from $\mathrm{Ti}$ and NiTi," Journal of Materials Chemistry, vol. 18, no. 12, pp. 13091317, 2008.

[17] G. P. Dinda, L. Song, and J. Mazumder, "Fabrication of Ti6Al-4V scaffolds by direct metal deposition," Metallurgical and Materials Transactions A, vol. 39, no. 12, pp. 2914-2922, 2008.

[18] J. Parthasarathy, B. Starly, S. Raman, and A. Christensen, "Mechanical evaluation of porous titanium (Ti6Al4V) structures with electron beam melting (EBM)," Journal of the Mechanical Behavior of Biomedical Materials, vol. 3, no. 3, pp. 249-259, 2010.

[19] P. Heinl, L. Muller, C. Korner, R. F. Singer, and F. A. Muller, "Cellular Ti-6Al-4V structures with interconnected macro porosity for bone implants fabricated by selective electron beam melting," Acta Biomaterialia, vol. 4, no. 5, pp. 1536-1544, 2008.

[20] P. Thomsen, J. Malmstrom, L. Emanuelsson, M. Rene, and A. Snis, "Electron beam-melted, free-form-fabricated titanium alloy implants: material surface characterization and early 
bone response in rabbits," Journal of Biomedical Materials Research B, vol. 90, no. 1, pp. 35-44, 2009.

[21] K. J. Kim, M. Iwase, S. Kotake, and T. Itoh, "Effect of bone marrow grafting on the titanium porous-coated implant in bilateral total knee arthroplasty," Acta Orthopaedica, vol. 78, no. 1, pp. 116-122, 2007.

[22] A. I. Caplan, "Mesenchymal stem cells," Journal of Orthopaedic Research, vol. 9, pp. 641-650, 1991.

[23] H. Tapp, E. N. Hanley Jr., J. C. Patt, and H. E. Gruber, "Adipose-derived stem cells: characterization and current application in orthopaedic tissue repair," Experimental Biology and Medicine, vol. 234, no. 1, pp. 1-9, 2009.

[24] T. Matsumoto, R. Kuroda, Y. Mifune et al., "Circulating endothelial/skeletal progenitor cells for bone regeneration and healing," Bone, vol. 43, no. 3, pp. 434-439, 2008.

[25] M. Jager, C. Zilkens, B. Bittersohl, and R. Krauspe, "Cord blood-an alternative source for bone regeneration," Stem Cell Reviews and Reports, vol. 5, no. 3, pp. 266-277, 2009.

[26] L. Danisovic, I. Varga, S. Polak, M. Ulicna, D. Bohmer, and J. Vojtassak, "Morphology of in vitro expanded human musclederived stem cells," Biomedical Papers of the Medical Faculty of the University Palacký, Olomouc, Czechoslovakia, vol. 152, no. 2, pp. 235-238, 2008.

[27] V. I. Sikavitsas, J. van den Dolder, G. N. Bancroft, J. A. Jansen, and A. G. Mikos, "Influence of the in vitro culture period on the in vivo performance of cell/titanium bone tissue-engineered constructs using a rat cranial critical size defect model," Journal of Biomedical Materials Research A, vol. 67, no. 3, pp. 944-951, 2003.

[28] J. W. Vehof, P. H. Spauwen, and J. A. Jansen, "Bone formation in calcium-phosphate-coated titanium mesh," Biomaterials, vol. 21, no. 19, pp. 2003-2009, 2000.

[29] J. S. Thalgott, C. Xiongsheng, and J. M. Giuffre, "Single stage anterior cervical reconstruction with titanium mesh cages, local bone graft, and anterior plating," Spine Journal, vol. 3, no. 4, pp. 294-300, 2003.

[30] G. Gastaldi, A. Asti, M. F. Scaffino et al., "Human adiposederived stem cells (hASCs) proliferate and differentiate in osteoblast-like cells on trabecular titanium scaffolds," Journal of Biomedical Materials Research A, vol. 94, no. 3, pp. 790-799, 2010.

[31] A. D. Ho, W. Wagner, and W. Franke, "Heterogeneity of mesenchymal stromal cell preparations," Cytotherapy, vol. 10, no. 4, pp. 320-330, 2008.

[32] W. Wagner and A. D. Ho, "Mesenchymal stem cell preparations-comparing apples and oranges," Stem Cell Reviews, vol. 3, no. 4, pp. 239-248, 2007.

[33] W. Wagner, P. Horn, M. Castoldi et al., "Replicative senescence of mesenchymal stem cells: a continuous and organized process," Plos One, vol. 3, no. 5, Article ID e2213, 2008.

[34] M. A. Baxter, R. F. Wynn, S. N. Jowitt, J. E. Wraith, L. J. Fairbairn, and I. Bellantuono, "Study of telomere length reveals rapid aging of human marrow stromal cells following in vitro expansion," Stem Cells, vol. 22, no. 5, pp. 675-682, 2004.

[35] G. M. de Peppo, S. Svensson, M. Lenneras et al., "Human embryonic mesodermal progenitors highly resemble human mesenchymal stem cells and display high potential for tissue engineering applications," Tissue Engineering A, vol. 16, no. 7, pp. 2161-2182, 2010.

[36] C. Karlsson, K. Emanuelsson, F. Wessberg et al., "Human embryonic stem cell-derived mesenchymal progenitorsPotential in regenerative medicine," Stem Cell Research, vol. 3, no. 1, pp. 39-50, 2009.
[37] G. M. De Peppo, P. Sjovall, M. Lenneras et al., "Osteogenic potential of human mesenchymal stem cells and human embryonic stem cell-derived mesodermal progenitors: a tissue engineering perspective," Tissue Engineering A, vol. 16, no. 11, pp. 3413-3426, 2010.

[38] K. Hjort and M. Theslof, Characterisation of Ti Scaffolds Made by FFF for Osteogenic Induction, Master Department of Materials and Manufacturing Technology, Chalmers University of Technology, Göteborg, Sweden, 2008.

[39] J. D. Roh, G. N. Nelson, B. V. Udelsman et al., "Centrifugal seeding increases seeding efficiency and cellular distribution of bone marrow stromal cells in porous biodegradable scaffolds," Tissue Engineering, vol. 13, no. 11, pp. 2743-2749, 2007.

[40] S. Rozen and H. Skaletsky, "Primer3 on the WWW for general users and for biologist programmers," Methods in Molecular Biology, vol. 132, pp. 365-386, 2000.

[41] K. Donath and G. Breuner, "A method for the study of undecalcified bones and teeth with attached soft tissues. The sageschliff (sawing and grinding) technique," Journal of Oral Pathology, vol. 11, no. 4, pp. 318-326, 1982.

[42] J. Parthasarathy, B. Starly, S. Raman, and A. Christensen, "Mechanical evaluation of porous titanium (Ti6Al4V) structures with electron beam melting (EBM)," Journal of the Mechanical Behavior of Biomedical Materials, vol. 3, no. 3, pp. 249-259, 2010.

[43] P. Heinl, A. Rottmair, C. Körner, and R. F. Singer, "Cellular titanium by selective electron beam melting," Advanced Engineering Materials, vol. 9, no. 5, pp. 360-364, 2007.

[44] R. O. Oreffo and J. T. Triffitt, "Future potentials for using osteogenic stem cells and biomaterials in orthopedics," Bone, vol. 25, no. 1, pp. S5-S9, 1999.

[45] P. J. Nelson and T. O. Daniel, "Emerging targets: molecular mechanisms of cell contact-mediated growth control," Kidney International, vol. 61, no. 1, pp. S99-S105, 2002.

[46] K. Vleminckx and R. Kemler, "Cadherins and tissue formation: integrating adhesion and signaling," BioEssays, vol. 21, no. 3, pp. 211-220, 1999.

[47] K. Xia, H. Xue, D. Dong et al., "Identification of the proliferation/differentiation switch in the cellular network of multicellular organisms," Plos Computational Biology, vol. 2, no. 11, article e145, 2006.

[48] M. P. Lynch, C. Capparelli, J. L. Stein, G. S. Stein, and J. B. Lian, "Apoptosis during bone-like tissue development in vitro," Journal of Cellular Biochemistry, vol. 68, no. 1, pp. 3149, 1998.

[49] U. Muller, T. Imwinkelried, M. Horst, M. Sievers, and U. Graf-Hausner, "Do human osteoblasts grow into open-porous titanium?” European Cells and Materials, vol. 11, pp. 8-15, 2006.

[50] T. Komori, "Cbfa1/Runx2, an essential transcription factor for the regulation of osteoblast differentiation," Nippon Rinsho, vol. 60, supplement, pp. 91-97, 2002.

[51] X. F. Tian, B. C. Heng, Z. Ge et al., "Comparison of osteogenesis of human embryonic stem cells within $2 \mathrm{D}$ and $3 \mathrm{D}$ culture systems," Scandinavian Journal of Clinical and Laboratory Investigation, vol. 68, no. 1, pp. 58-67, 2008.

[52] T. Komori, "Runx2, a multifunctional transcription factor in skeletal development," Journal of Cellular Biochemistry, vol. 87, no. 1, pp. 1-8, 2002.

[53] S. Fujibayashi, M. Neo, H. M. Kim, T. Kokubo, and T. Nakamura, "Osteoinduction of porous bioactive titanium metal," Biomaterials, vol. 25, no. 3, pp. 443-450, 2004.

[54] T. Tadic, I. Erceg, M. L. Stover, D. W. Rowe, and A. C. Lichtler, "Dlx5 induces expression of COL1A1 promoter contained in 
a retrovirus vector," Croatian Medical Journal, vol. 42, no. 4, pp. 436-439, 2001.

[55] S. Rajwant, L. P. Z. Bedi, and Y. Yushan, "Osteoconductive and osteoinductive properties of zeolite MFI coatings on titanium alloys," Advanced Functional Materials, vol. 19, no. 24, pp. 3856-3861, 2009.

[56] R. S. Siffert, "Alkaline phosphatase and contractile proteins," The Journal of Experimental Medicine, vol. 93, pp. 415-426, 1951.

[57] E. Mornet, E. Stura, A. S. Lia-Baldini, T. Stigbrand, A. Menez, and M. H. Le Du, "Structural evidence for a functional role of human tissue nonspecific alkaline phosphatase in bone mineralization," Journal of Biological Chemistry, vol. 276, no. 33, pp. 31171-31178, 2001. 


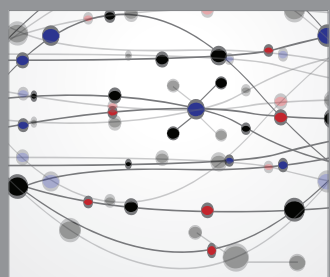

The Scientific World Journal
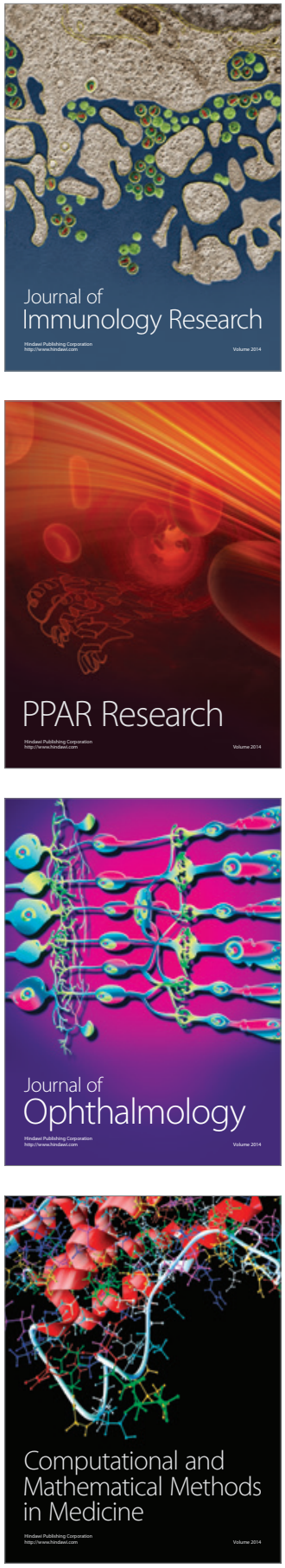

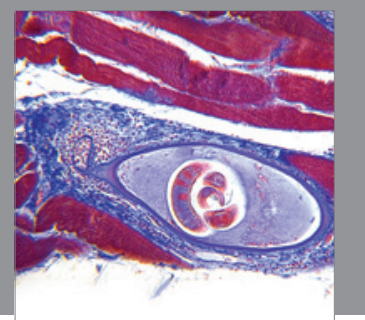

Gastroenterology

Research and Practice
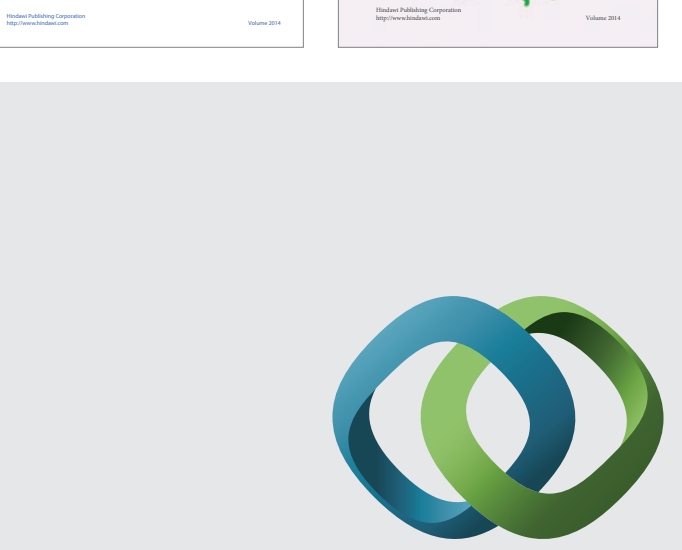

\section{Hindawi}

Submit your manuscripts at

http://www.hindawi.com
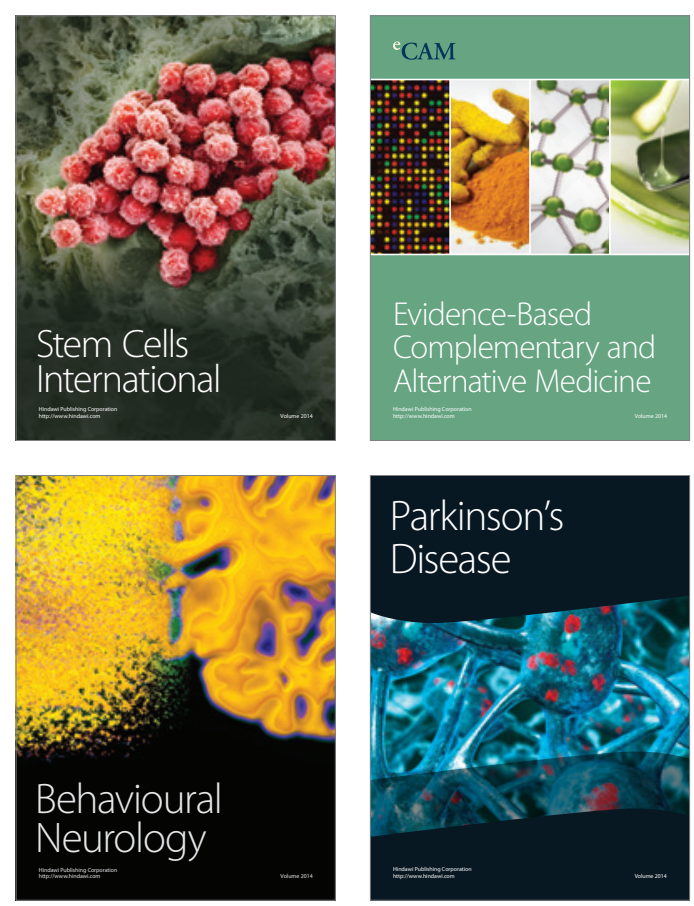

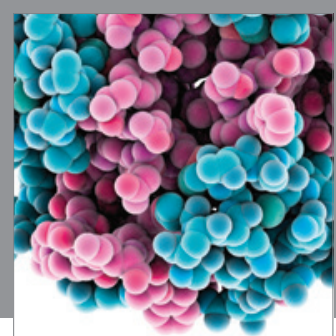

Journal of
Diabetes Research

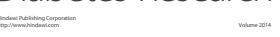

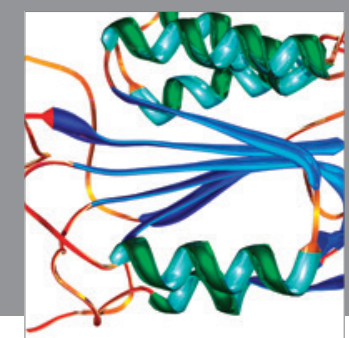

Disease Markers
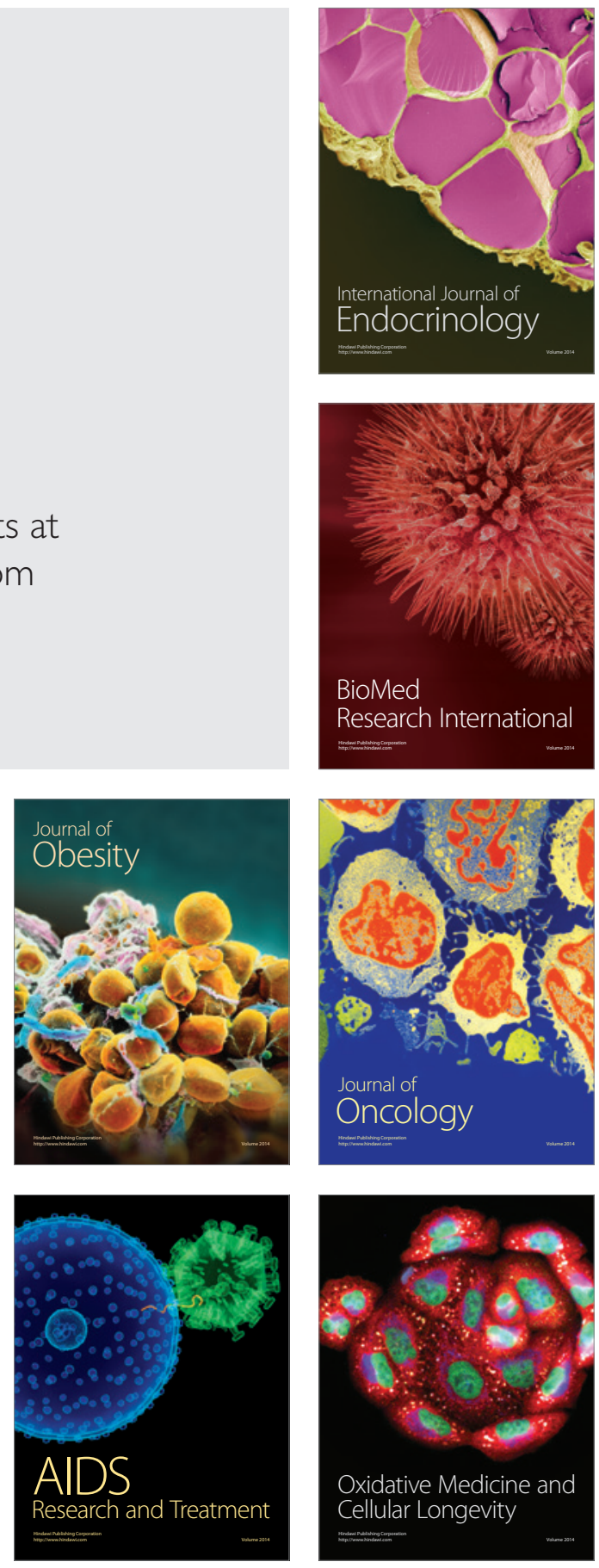